\title{
RELEVANCE OF MID ARM CIRCUMFERENCE AS AN ANTHROPOMETRIC TOOL IN ADOLESCENTS.
}

\section{Subha Sankar Dutta \\ Arunabha Tapadar}

Kana Bal*

\section{Assistant Professor, Department of Anatomy, Malda Medical College, West} Bengal

Professor and Head, Department of Anatomy, Raiganj Govt. Medical College, West Bengal

Associate Professor, Nil Ratan Sircar Medical College, Kolkata, West Bengal ${ }^{*}$ Corresponding Author

\section{ABSTRACT}

The mid arm circumference (MAC) is an anthropometric tool for measurement of nutritional adequacy and growth in the "under five' paediatric age group. However in adolescent children it is important in rapid and mass surveys. The MAC was measured in 130 healthy school children (84 boys and 46 girls) of 12 - 14 years age of M.G.M's Sanskar Vidyalaya, N-4 Cidco, Aurangabad using the girth of the arm at the midpoint between the acromial process of the scapula and the lateral epicondyle of the humerus. The study aims to measure the MAC in an adolescent population and compare them with data from previous studies in an attempt to formulate $\alpha$ "normal" range for comparison with similar studies. In the present study, the MAC for 12 year old children varies from $18.81-20.7 \mathrm{~cm}$, for 13 year old children from $20.4-20.82 \mathrm{~cm}$ and 14 year old children from $21.12-21.97 \mathrm{~cm}$. The present study gives us a range of $\sim 19-22 \mathrm{~cm}$ as the range of MAC in adolescent boys and girls. In spite of several studies on the MAC in adolescents, no consensus has been reached regarding the cut off points for determining under nutrition and overweight. Further studies are required to publish the normal cut off ranges of MAC for the adolescent population of our country.

\section{KEYWORDS : midarm circumference, adolescent, anthropometry}

\section{Introduction}

Measurements of the human body have fascinated us from antiquity. The ideal of a perfect human form has always been extensively debated. We have tried our hardest to arrive at standards of body measurement which will enable us to detect with a good amount of certainty the deviations from the normal in a population of human beings. Scientists and laymen alike have tried to correlate the relationships of different body parts to arrive at a conclusion regarding the overall health of an individual. With the evolution of the human race and colonization of almost of the landmass of the earth, it has become increasingly difficult to lay down standards of physical measurement applicable to all. As a result different groups of investigators have dealt with the measurements of different races of people and tried to set up standards of normal growth and development for local and global use.

The mid arm circumference (MAC) has been used in modern medical practice to assess both bone and soft tissue growth, particularly muscle mass and adipose tissue. It has been used as an anthropometric tool in determining the level of nutrition in an individual. The measurement has been found to be more relevant in children below the age of 5 years and elderly people. This is because childhood is the period of rapid and predictable growth where deviations from the normal are evident. On the other hand elderly people are in a phase of steadily declining growth along with gradual loss of muscle mass, which again is quite noticeable. MAC measurements can be used to indicate malnutrition when measurement of weight or height is not feasible [Ververs 2013]. Different countries have set up standards of the MAC along with growth charts applicable to the local population.

In the adolescent population, the MAC has not been properly evaluated. This is the period of the "growth spurt" and so the MAC should be able to detect both under nutrition and obesity, if reliable standards and data are available for comparison. The accelerated growth phase in this period usually determines the adult body proportions. It should be kept in mind that the MAC is an anthropological parameter that can be measured most easily and with the minimum of fuss. It requires just a measuring tape and nothing else. At the present time a limited number of studies are available for comparison.

The present study attempts to find the utility of measuring the MAC in an adolescent student population in a semi urban setup.

\section{Materials \& methods}

The present study was carried out on a population of 130 students ( 84 boys and 36 girls) from 12 to 14 years of age, in the Department of Anatomy, Mahatma Gandhi Mission's Medical College, Aurangabad, Maharashtra. The students were taken from Mahatma Gandhi Mission's Sanskar Vidyalaya, Aurangabad.

The midpoint of the arm was the centre of a line marked from the acromial process of scapula in the shoulder region to the head of radius felt in the depression on the posterolateral aspect of the elbow distal to the lateral epicondyle of humerus. The subject was made to stand erect with the superior extremity fully extended at the elbow.

The upper limb was kept at the side of the trunk and the palm faced inwards. Then the measuring tape was placed around the midpoint of the arm snugly but without compressing the skin. This gave us the mid arm circumference [Gibson]. For mass programs, the UNICEF recommends a Mid Upper Arm Circumference measuring tape specially developed by them. The adult version of this tape is suitable for measurements in adolescent children. The first insertion type tapes were used by Jelliffe in the 1960's and a colour coded wrap-around type tape was used by the Iraqi paediatrician Adnam Shakir in the 1970's which became famous as the "Shakir strip".

At the time of recording the MAC, the subject's weight and height were measured and the Body Mass Index (BMI) was calculated. This was done to judge whether the person concerned was of normal, over or under weight. 
Inclusion criteria

All students of the school between the ages of 12 and 14 who volunteered to participate in the study were included.

\section{Exclusion criteria}

Any student having a bony or soft tissue deformity of an arm or with evidence of healed fractures was excluded from the study.

\section{Results}

Table 1. Showing mean of Mid Arm Circumference (cm) both arms at different age groups.

\begin{tabular}{|c|c|c|c|c|}
\hline \multirow{2}{*}{$\begin{array}{c}\text { Age } \\
\text { group }\end{array}$} & \multicolumn{3}{|c|}{ Mid Arm Circumference (cm) - mean values } \\
\cline { 2 - 5 } & \multicolumn{2}{|c|}{ Male } & \multicolumn{2}{c|}{ Female } \\
\cline { 2 - 5 } & Right arm & Left arm & Right arm & Left arm \\
\hline 12 & 18.94 & 18.81 & 20.07 & 19.87 \\
\hline 13 & 20.27 & 20.04 & 21.02 & 20.82 \\
\hline 14 & 21.40 & 21.12 & 21.72 & 21.97 \\
\hline
\end{tabular}

Fig.2. Midarm circumference of right arm of the study population

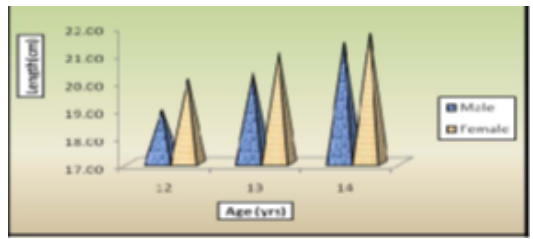

From Table 1 \& Fig.2, it was observed that in the age group of 12 yrs the average right mid arm circumference was more in females than in males by $1.13 \mathrm{~cm}$.

In the age group of 13 years, right mid arm circumference was more in females by $0.75 \mathrm{~cm}$.

In age group of 14 years average right mid arm circumference was more in females by $0.32 \mathrm{~cm}$.
In males between 12 to 13 years the right mid arm circumference increased by $1.33 \mathrm{~cm}$ and between 13 to 14 years the right mid arm circumference increased by $1.13 \mathrm{~cm}$.

In females from 12 and 13 years the right mid arm circumference increased by $0.95 \mathrm{~cm}$ and between 13 to 14 years the right mid arm circumference increased by $0.7 \mathrm{~cm}$.

Fig, 3. Midarm circumference of left arm of the study population

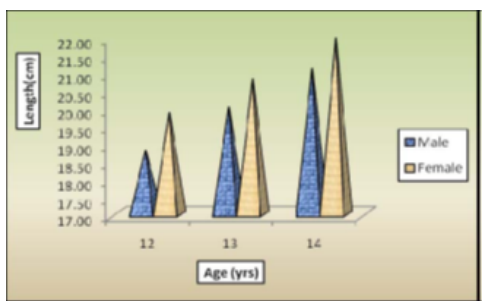

From Tables 1 \& 3, it was observed that in the age group of 12 yrs the average right mid arm circumference was more in females than in males by $1.06 \mathrm{~cm}$.

In the age group of 13 years, left mid arm circumference was more in females by $0.78 \mathrm{~cm}$.

In age group of 14 years average left mid arm circumference was more in females by $0.85 \mathrm{~cm}$.

In males between 12 to 13 years the left mid arm circumference increased by $1.23 \mathrm{~cm}$ and between 13 to 14 years the left mid arm circumference increased by $1.08 \mathrm{~cm}$.

In females between 12 and 13 years the left mid arm circumference increased by $0.95 \mathrm{~cm}$ and between 13 to 14 years the left mid arm circumference increased by $1.15 \mathrm{~cm}$.

Table. 2. Arm circumference, sexes separate (Jelliffe, 1966)

\begin{tabular}{|c|c|c|c|c|c|c|c|c|c|c|}
\hline \multirow[t]{3}{*}{ Age (years) } & \multicolumn{10}{|c|}{ Ärm circumference (cm) } \\
\hline & \multicolumn{2}{|c|}{ Standard } & \multicolumn{2}{|c|}{$90 \%$ Standard } & \multicolumn{2}{|c|}{$80 \%$ Standard } & \multicolumn{2}{|c|}{$70 \%$ Standard } & \multicolumn{2}{|c|}{$60 \%$ Standard } \\
\hline & $\mathrm{M}$ & $\mathrm{F}$ & $\mathbf{M}$ & $F$ & $\mathbf{M}$ & $F$ & $\mathbf{M}$ & $F$ & $\mathbf{M}$ & $F$ \\
\hline 12 & 21.2 & 21.5 & 19.1 & 19.3 & 16.9 & 17.2 & 14.8 & 15.0 & 12.7 & 12.9 \\
\hline 13 & 22.2 & 22.4 & 20.0 & 20.2 & 17.7 & 17.9 & 15.5 & 15.7 & 13.3 & 13.4 \\
\hline 14 & 23.2 & 23.2 & 20.9 & 20.9 & 18.6 & 18.5 & 16.2 & 16.2 & 13.9 & 13.9 \\
\hline
\end{tabular}

\section{DISCUSSION}

The mid arm circumference (MAC) is a useful anthropometric tool in assessment of nutritional status. It is simple to measure, requires no calculations and can be reliably performed by untrained individuals. It can also be performed in large number of individuals in a short time. Several authors have shown that the MAC cab be correlated with the total fat content of the human body and be used as an index of nutrition in children, adolescents and adults [Chomtho, Tang].

Traditionally MAC has been used in the under 5 children for nutritional assessment. However, in recent times there has been a resurgence of MAC measurement in adolescents and adults as an anthropometric measure, particularly in areas of civil unrest and war. The large number of displaced persons suffering from nutritional deprivation requires rapid and reliable measurements of nutritional adequacy and growth for prioritization of humanitarian aid. Although such data is available for children, there is a lack of data for adolescents.

The adolescent age group is supposed to extend from the age of 10 to 19 years, of which early adolescence is from 10 to 14 years and late adolescence from 15 to 19 years [WHO 2007].

Anthropometric measurements of the Indian population are closely comparable to the population of South East Asian countries and the people of the Middle East but differ significantly from the Caucasians. However, criteria vary from country to country are there are few global standards.

Ozturk et al in 2009 found the MAC $50^{\text {th }}$ percentile in a polulation of Turkish adolescents to range from 17.0 to $23.6 \mathrm{~cm}$ in boys, and from $15.6 \mathrm{~cm}$ to $20.9 \mathrm{~cm}$ in girls.

In another South African study, boys with a MAC of $>22.8 \mathrm{~cm}$ and girls with a MAC of $>22.15 \mathrm{~cm}$ were considered to be overweight [Craig]. In an important study carried out by Tang et al in 2013, it was shown that the incidence of anemia is more prevalent in adolescent girls with a mid arm circumference of $<22 \mathrm{~cm}$.

In another study carried out on adolescent girls in Maharashtra, by [Jeyakumar] et al it was seen that the Mean $\mathrm{MAC} \pm \mathrm{SD}$ in cm was $22.84 \pm 2.21$. A similar study carried out on adolescent boys in Kolkata revealed the values of MAC in $\mathrm{cm} \pm \mathrm{SD}$ as $18.5 \pm 2.18,21.11 \pm 3.41 \& 21.64 \pm 3.19$ in the age groups of 12,13 and 14 years respectively [Dasgupta].

In the present study it is apparent that the MAC in females is greater than that of the males as the adolescent growth spurt starts earlier in females. By the age of 13 , the growth in males has accelerated and narrowed the gap and by the age of 14 , the MAC is greater in males than in females. 
Standards of the mid arm circumference for adolescents are hard to come by. One of the most reliable data available is that of [Jelliffe] (1966) which was collated from data collected from surveys in developing countries. The standards presented in that monograph are as follows -

In the present study, the MAC for 12 year old males varies from $18.81 \mathrm{~cm}$ to $18.94 \mathrm{~cm}$ which lies between $80 \%$ \& $90 \%$ of Jelliffe's standard. All other MAC values for the right and left arms in males and females lie between $90 \%$ \& $100 \%$ of the standard for their particular ages. This shows that the data compiled by Jelliffe may be used as an Indian standard for the time being until larger series of data are available and a consistent effort is made to create Indian standards of Mid Arm Circumference for use in nutritional assessment both of under nutrition and overweight / obesity.

Another available MAC reference is the NHANES (National Health and Nutritional examination Survey) 2003-06 conducted by Centres for Disease Control (CDC), National Centre for Health Statistics (NCHS). $25.4 \pm 6.91 \mathrm{~cm}, 26.8 \pm$ $6.38 \mathrm{~cm}$ and $27.7 \pm 6.4 \mathrm{~lm}$ ( Mean $\pm \mathrm{SD}$ ) [Dasgupta]. However, these data are in a much higher range and do not appear to be consistent with the measurements in an Indian population.

\section{CONCLUSION}

The present study illustrates the utility of measuring the mid arm circumference as an anthropometric indicator of nutrition. Although measurements of the MAC have been carried out on different series of adolescents from time to time, no consensus has been reached regarding the cut off points for determining under nutrition and overweight. There is thus insufficient evidence in favour of any MAC cut off which optimizes sensitivity and specificity for any particular population. The present study however gives us a range of $\sim 19 \mathrm{~cm}-22 \mathrm{~cm}$ as the range of values for MAC in adolescent boys and girls. Further studies are required on different groups of children in an attempt to publish the normal cut off ranges of MAC applicable to the adolescent population of our country.

\section{REFERENCES}

- Ververs, M.; Antierens, A.; Sackl, A.; et al. 2013. "Which anthropometric indicators identify a pregnant woman as acutely malnourished and predict adverse birth outcomes in the humanitarian context?" PLOS Current Disasters. 1-13.

- Gibson, R.S. 2005. Principles of Nutritional Assessment. Second ed. Oxford: Oxford University Press.

- Chomtho S, Fewtrell MS, Jaffe A, Williams JE, Wells JC. Evaluation of arm anthropometry for assessing pediatric body composition: evidence from healthy and sick children. Pediatr Res. 2006;59(6):860-5.

- Tang A, Dong K, Deitchler M, Chung M, Maalouf-Manasseh Z, Tumilowitz A, et al. Use of cutoffs for mid upper arm circumference (MUAC) as an indicator or predictor of nutritional and health-related outcomes in adolescents and adults: A systematic review. Washington, DC: United States: 2013.

- WHO Regional Office For South East Asia, New Delhi-Adolescent Health At A Glance in South East Asia Region 2007.

- Ozturk A, Budak N, Cicek B, Mazicioglu MM, Bayram F, Kurtoglu S. Crosssectional reference values for mid-upper arm circumference, triceps skinfold thickness and arm fat area of Turkish children and adolescents. Int J Food Sci Nutr. 2009;60(4):267-81.

- E Craig, R Bland, J Ndirangu, J J Reilly Use of mid-upper arm circumference for determining overweight and overfatness in children and adolescents Arch Dis Child 2014;99:763-766.

- Angeline Jeyakumar, Padmini Ghugre, and Swapnil Gadhave. Mid-UpperArm Circumference (MUAC) as a Simple Measure to Assess the Nutritional Status of Adolescent Girls as Compared With BMI. ICAN: Infant, Child, \& Adolescent Nutrition. February 2013.

- Aparajita Dasgupta, Arindam Butt, Tushar Kanti Saha, Gandhari Basu, Amitava Chattopadhyay, and Anindya Mukherjee, Assessment of Malnutrition Among Adolescents:Can BMI be Replaced by MUAC. Indian J Community Med. 2010 Apr; 35(2): 276-279.

- Jelliffe D.B. The assessment Of Nutritional Status In The Community. World Health Organization Monograph No. 53, 1966 